\title{
PLACA DENTAL E ÍNDICE DE HIGIENE ORAL
}

\section{SINOPSE}

Em um grupo de indivíduos selecionados, é feita uma comparação dos Indices de Higiene Oral pelo método de Greene e Vermillion, sem e com o uso de revelador, com o objetivo de saber das vantagens ou não do emprêgo de reveladores para melhor identificar os depósitos dentais.

\section{INTRODUÇAO}

Existem vários índices de cárie dental, doença periodontal e de higiene oral, com o objetivo de fazer levantamentos estatísticos para fins epidemiológicos. Todos êles têm por finalidade, dar uma idéia global ou em percento, do número de peças ou áreas atingidas por cárie, doença periodontal e depósitos sôbre as superfícies dentais expostas. Ao mesmo tempo, o número do índice

\section{Luiz Carlos Tovo}

Professor Adjunto do Departamento de Odontologia Preventiva e Social

final representa o número de peças ou áreas que estão atingidos por qualquer uma das alterações acima referidas, sendo que apenas os índices de doença periodontal dão uma idéia da extensão em profundidade do problema.

0 índice de higiene oral (IHO), normalmente inclui o índice de matéria mole bem como o de cálculo, sôbre as superfícies dentais expostas.

o critério adotado para a leitura do depósito dental, informa a extensão da área dental atingida, por superfície coronária ou radicular, mas não informa $o$ volume de material depositado.

Evidentemente, se quiséssemos avaliar o volume dos depósitos teríamos que medir em pêso, todo material depoistado, o que seria extremamente difícil, ou mesmo, impossível. Todavia, se dispusermos de artifícios que nos permitam maior 
acuidade e alcance do material depositado, teremos uma informação mais fiel e mais real do volume depositado.

Com êste intuito, fizemos um levantamento de IHO pelo método de GREENE e VERMILLION ${ }^{1}$, 1960, índice largamente recomendado e usado, de um grupo de individuos e o comparamos com ' o mesmo índice, nos mesmos indivíduos, porém, fazendo a leitura dos depósitos com o auxílio de um revelador (IHOR), em vez de, uma sonda exploradora.

\section{MATERIAL E MÉTODO}

A leitura do IHO foi realizada em um grupo de 38 alunos, de 18 a 25 anos de idade, da F.O.P.A. da U.F.R.G.S., que foram separados em quatro grupos, dois com índice de cárie (IC) baixo, em relação aos outros dois grupos, com IC alto.

Para cada grupo, IC alto e IC baixo, havia metade dos indivíduos com cárie e outra metade sem cárie.

O IC foi estabelecido de acôrdo com VIEGAS ${ }^{4}$, 1952, realizando-se exame com sonda, espêlho, ar e «bite-wing».

Antes de ser feita a leitura do IHO, os alunos bochechavam, ràpidamente, um pouco de água que era despejada sôbre a bochecha com uma seringa.

Após, um único operador, com o auxílio de odontoscópio e sonda exploradora, fazia a leitura das áreas atingidas, enquanto um auxiliar anotava-as em ficha individual.

Imediatamente, as arcadas dentais eram pinceladas com um algodão frouxo na extremidade de uma pinça, embebido com o revelador de SKINNER $^{3}$, seguido de um bochecho com água, rápido e nova leitura e anotação pelos̃ mesmos operadores.

Fórmula de SKINNER $^{3}$ modificada

Iodeto de $\mathrm{Zn}$ ou $\mathrm{K} \ldots \ldots .12 \mathrm{~g}$

Água destilada .......... $8 \mathrm{ml}$ Glicerina ............. $40 \mathrm{ml}$ Iôdo ................ $20 \mathrm{~g}$

Nota: para o preparo fazer a mistura pela ordem descrita acima.

Ao se fazer a inspeção com a sonda exploradora, não se constatou em nenhum dos indivíduos, depósito calcificado, supra ou subgengival.

Devidamente anotadas as áreas com depósitos, de acôrdo com o critério de GREENE e VERMILLION ${ }^{1}$, 1960 , foram computadas e calculado o IHO individual, bem como o IHOR.

Fêz-se após, o cálculo de «t» (Teste de STUDENT) para saber da significância ou não, dos valôres encontrados para o IHO e o IHOR, dos 38 indivíduos nos quatro grupos estudados.

\section{RESULTADOS}

Os índices obtidos dos 38 indivíduos estão descritos, a seguir, em cada um dos quatro grupos estudados. 


\begin{tabular}{|c|c|c|c|c|c|c|c|c|c|c|c|}
\hline \multicolumn{6}{|c|}{$\begin{array}{l}\text { GRUPOS COM DENTES } \\
\text { CARIADOS }\end{array}$} & \multicolumn{6}{|c|}{$\begin{array}{l}\text { GRUPOS SEM DENTES } \\
\text { CARIADOS }\end{array}$} \\
\hline \multicolumn{3}{|c|}{ GRUPO 1} & \multicolumn{3}{|c|}{ GRUPO 2} & \multicolumn{3}{|c|}{ GRUPO 3} & \multicolumn{3}{|c|}{ GRUPO 4} \\
\hline IC & IHO & IHOR & IC & IHO & IHOR & IC & IHO & IHOR & IC & IHO & IHOR \\
\hline 10.1 & 1.0 & 1.8 & 32.6 & 0.3 & 2.5 & 6.9 & 0 & 1.8 & 38.7 & 0.8 & 1.8 \\
\hline 10.3 & 0.8 & 2.3 & 33.7 & 0.4 & 2.3 & 10.3 & 0.8 & 2.6 & 38.1 & 1.8 & 4.5 \\
\hline 10.3 & 1.6 & 2.1 & 35.8 & 0.3 & 3.1 & 11.4 & 0.4 & 2.0 & 38.1 & 0.5 & 2.3 \\
\hline 10.6 & 2.1 & 3.1 & 35.3 & 2.1 & $\mathrm{x}$ & 11.8 & 0.8 & 3.1 & 39.3 & 1.6 & 4.5 \\
\hline 12.0 & 0.3 & 2.8 & 39.1 & 0.6 & 3.6 & 11.9 & 0 & 0.8 & 39.6 & 0.6 & 2.3 \\
\hline 14.1 & 1.5 & 3.1 & 37.2 & 0.6 & 3.0 & 13.2 & 0.6 & 3.0 & 41.8 & 1.1 & 2.3 \\
\hline 15.0 & 0.6 & 1.8 & 38.3 & 2.1 & 4.0 & 14.0 & 0.6 & 3.0 & 41.8 & 0.1 & 2.5 \\
\hline 15.2 & 1.5 & 2.8 & 41.3 & 1.2 & 2.5 & 14.6 & 0.5 & 3.3 & 42.8 & 0.6 & 2.0 \\
\hline 15.2 & 1.6 & 3.5 & 41.3 & 1.0 & 2.6 & 15.0 & 0.5 & 3.3 & 48.8 & 0 & 0.3 \\
\hline 15.7 & 0.6 & 2.0 & 43.8 & 1.9 & 2.1 & 15.2 & 1.5 & 3.5 & $\mathrm{x}$ & $\mathrm{x}$ & $x$ \\
\hline
\end{tabular}

A soma de cada grupo, bem como a soma total do IHO e IHOR, foi a seguinte:

\section{GRUPO IHO IHOR}

$\begin{array}{crr}1 & 11.6 & 25.3 \\ 2 & 8.4 & 25.7 \\ 3 & 5.7 & 26.4 \\ 4 & 7.1 & 22.5 \\ \text { Total } & -32.8 & 99.9\end{array}$

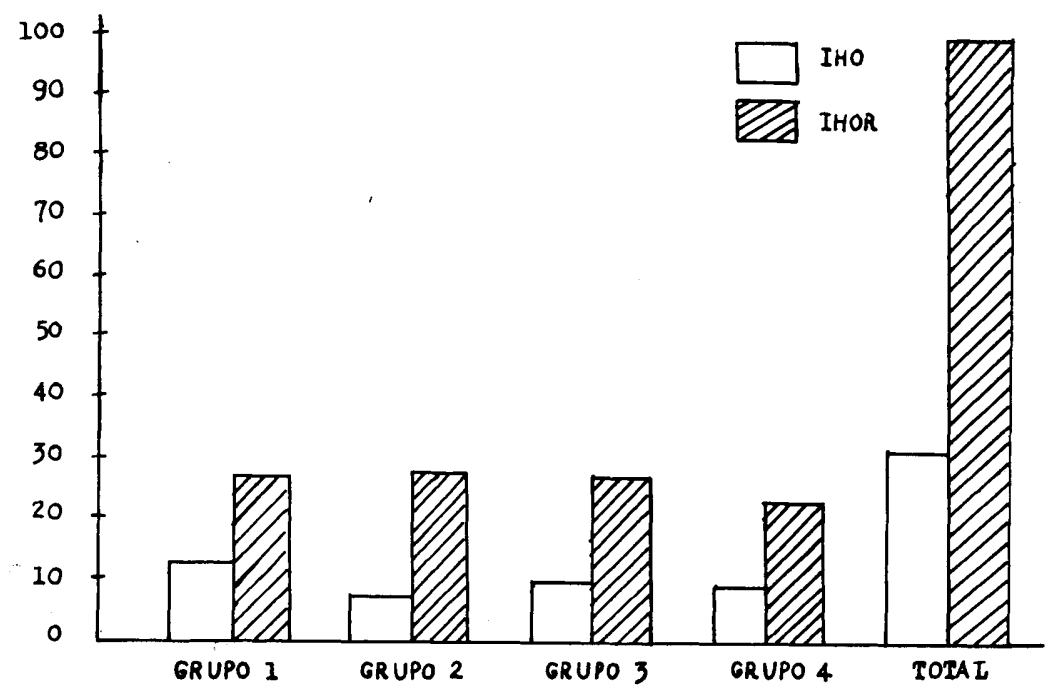

R. Fac. Odont. P. A. 


\section{DISCUSSÃO}

Usamos o índice de GREENE e VERMILLION $^{1}, 1960$, porque pareceu-nos ser mais objetivo e rápido na obtenção do que outros de nosso conhecimento, como o índice de placa de SILNESS e LöE2 2 , 1964, que em última análise é uma adaptação do índice anterior e nos conduziria a um mesmo resultado.

De qualquer maneira, a avaliação com o método usado, onde se mede a extensão de matéria mole (matéria «alba») e cálculo dental, depositados sôbre as superfícies dentais, subentende placa dental, pois os depósitos citados são sempre continuidade da placa dental, prèviamente formada.

Nos índices obtidos de IHO e IHOR, todavia, não se consegue avaliar com fidelidade os potenciais odonto ou periodontopáticos dos depósitos de placa dental.

Com o uso de revelador identificase a totalidade da extensão da placa dental, dando-nos uma melhor idéia do volume da placa e da área dental atingida pelos depósitos.

Para exemplificarmos, tomemos os casos dos indivíduos que tinham o IHO igual a zero ou quase zero. Dois indivíduos com zero, após o uso do revelador, passaram os indices para, um 0.3 e outro 0.8 , o que significa apreciável depósito considerando-se que êste índice varia de zero a 6 , e isto representa depósito de placa dental não visualizado, sem revelador.

Dos indivíduos próximos de zero tomemos de cinco casos:

IHO de 0.1 passou para $2.5 \mathrm{com}$ revelador, e sucessivamente de 0.3 para 2.5 , de 0.3 para 2.8 , de 0.3 para 3.1 , e de 0.4 para 2.3. O total dêstes cinco casos atingiu IHO 1.4 e IHOR 13.2, o que significa que o revelador mostrou cêrca de dez vêzes mais material depositado.

Os resultados demonstram, claramente, que sòmente cêrca de $30 \%$ dos depósitos dentais é que são avaliados, pelo método experimentado (IHO), pois a observação macroscópica que é realizada, não permite a identificação dos restantes $70 \%$, constituído, bàsicamente de placa dental e sòmente visíveis com o uso de corantes reveladores (IHOR).

\section{CONChUSÃO}

Face aos resultados encontrados, faz-se óbvia a recomendação de corantes reveladores, tanto para levantamentos de indices de depósitos dentais, bem como, para a identificação e extensão dos mesmos a fim de serem removidos e ainda, para emprêgo em clientes com a finalidade de educá-los para uma boa higiene oral.'

\section{SYNOPSIS}

In a group of selectioned humans a comparation is made of the Oral Hygiene Index by GREENE and VERMILILON method's with and without use of disclosing agent with the purpose of knowing the advantages or no about this method. 


\section{REFERENCIAS BIBLIOGRÁFICAS}

1. GREenE, J. C. \& Vermillion, J. R. - The oral hygiene index; a method for classifying oral higyene status. Journal of American Dentalo Association, Chicago, 61:172-179, 1960.

2. SILNESS, J. \& LöE, H. - Periodontal disease in pregnancy. II. Correlation between oral hygiene and periodontal condition. Acta Odontologica Scandinavica, Stockholm, 22:121-135, 1964.

3. SKINNER, apud BUNTING, W. R. et alii - Oral Hygiene, 2. ed., Philadelphia, Lea \& Febiger, 1954, 283 p. (p. 237).

4. viegas, A. R. - Índice de cárie. Revista da Associação Paulista de Cirurgiões Dentistas, São Paulo, 5:13-23, 1952. 